Análise do Comportamento e Fisiologia

\title{
Fronteiras entre Análise do Comportamento e Fisiologia: Skinner e a Temática dos Eventos Privados
}

\author{
Emmanuel Zagury Tourinho ${ }^{12}$ \\ Eveny da Rocha Teixeira \\ Josiane Miranda Maciel \\ Universidade Federal do Pará
}

\begin{abstract}
Resumo
O presente estudo examinou referências de B. F. Skinner à fisiologia em textos sobre eventos privados, com o objetivo de identificar elementos para uma demarcação mais precisa das relações entre análise do comportamento e fisiologia. As contribuições de Skinner naquela direção foram categorizadas em seis temas: a) variáveis biológicas como constitutivas, mas não definidoras do fenômeno comportamental privado; b) autonomia do recorte analítico-comportamental diante dos fatos biológicos/fisiológicos; c) limites de controle do comportamento por eventos internos/fisiológicos; d) comportamento privado como comportamento do organismo como um todo; e) distinção entre contato privilegiado e conhecimento privilegiado; e f) preservação do recorte analítico-comportamental em situação de análise aplicada do comportamento. As proposições correspondentes às categorias descritas são apontadas como originais na definição do campo de uma ciência do comportamento e capazes de orientar coerentemente a demarcação das fronteiras entre análise do comportamento e fisiologia enquanto disciplinas independentes e complementares.

Palavras-chave: Behaviorismo radical; análise do comportamento; fisiologia; eventos privados.
\end{abstract}

Boundaries Between Behavior Analysis and Physiology:

Skinner and the Issue of Private Events

Abstract

This study examines B. F. Skinner's references to physiology in publications dealing with private events, in order to identify elements for a clearer definition of the relations between behavior analysis and physiology. Skinner's contributions were analyzed with reference to six thematic categories: a) biological variables as constitutive, albeit non-defining properties of private behavioral phenomena; b) the autonomous nature of the behavioral-analytical approach in the face of biological/ physiological facts; c) limits of behavior control by internal/physiological events; d) private behavior as behavior of the physiological facts; c) limits of behavior control by internal/physiological events; d) private behavior as behavior of the
organism as a whole; e) a distinction between privileged access and privileged knowledge; f) retention of the behavioralanalytical approach in applied behavior analysis. Skinner's propositions concerning the described categories are discussed as original in defining the field of a science of behavior and capable of providing a coherent guide for establishing clear-cut limits between behavior analysis and physiology as independent and complementary disciplines.

Keywords: Radical behaviorism; behavior analysis; physiology; private events.

A relação entre a análise do comportamento e sistemas diversos para a explicação do comportamento humano pode ser abordada sob duas perspectivas, a princípio distintas. A análise do comportamento pode ser confrontada com modelos tipicamente psicológicos, mas claramente concorrentes, por exemplo, o cognitivismo

Endereço para correspondência: Rua Boaventura da Silva, 1251/1402. 66.060-060, Belém, Pará. Fone: (91) 211-1453. Fax: (91) 211-1662 Email: tourinho@amazon.com.br

2 Notas dos autores e agradecimentos: Trabalho parcialmente financiado pelo CNPq, através da concessão de bolsa de Produtividade em Pesquisa e bolsas de Iniciação Científica. Uma versão preliminar foi apresentada na XXVIII Reunião Anual da Sociedade Brasileira de Psicologia, Ribeirão Preto, outubro de 1998 . (cf. Flora \& Kestner, 1995; Moore, 1975; 1981; Overskeid, 1994; Skinner, 1985, 1989c; Stemmer, 1995) e pode ser confrontada com disciplinas afins, mas independentes, como exemplo, a fisiologia (cf. Baer, 1996; Bullock, 1996; Donahoe, 1996; Donahoe \& Palmer, 1994; Moore, 1997; Poling \& Byrne, 1996; Reese, 1996a, 1996b). Pode-se supor que, no primeiro caso, a questão é de opção entre perspectivas irreconciliáveis de análise, enquanto, no segundo, o problema é meramente de demarcação de fronteiras. Esta formulação pode ser insuficiente diante de versões do cognitivismo que se apropriam do conhecimento construído no âmbito das neurociências, tornando-o parte de seus recursos explicativos para o 
comportamento humano (cf. Skinner, 1990). Uma análise do debate sobre as relações entre análise do comportamento e fisiologia mostra também que a questão é polêmica, mesmo quando não se transita para o campo das teorias cognitivistas (cf. Tourinho, 1999).

O tema dos eventos privados está entre aqueles que assumem certa centralidade quando as relações entre análise do comportamento e fisiologia são discutidas, em parte devido à freqüente definição skinneriana de privado como evento interno. Tourinho (1997) aponta algumas dificuldades geradas por aquela definição, bem como sua insuficiência diante de princípios mais básicos que orientam a interpretação behaviorista radical para o comportamento humano complexo. Uma vez que a identificação do privado com o aparato anátomo-fisiológico se mostra problemática, especialmente porque pode favorecer novas versões de internalismo, interditando as análise tipicamente externalistas e relacionais que caracterizam o recorte de uma ciência do comportamento, mostra-se ainda necessário esclarecer como se organiza a referência à fisiologia numa interpretação behaviorista radical para os eventos privados.

Admitindo-se que as afirmações skinnerianas a respeito do assunto não são sempre consistentes (cf. Hayes, 1994 Reese, 1996a; Tourinho, 1997), não se pretende reiterar os problemas derivados da associação eventual entre privado e interno. O objetivo deste trabalho foi identificar, em textos do próprio Skinner sobre eventos privados, elementos para uma demarcação mais precisa das fronteiras entre análise do comportamento e fisiologia. O estudo teve como base textos de Skinner (de 1945 1990) nos quais a problemática dos eventos privados é abordada. As referências à fisiologia foram categorizada e analisadas em seis temas: as variáveis biológicas como constitutivas, mas não definidoras do fenômeno comportamental privado; a autonomia do recorte analítico-comportamental diante dos fatos biológicos/ fisiológicos; os limites do controle do comportamento por eventos internos/fisiológicos; o comportamento privado como comportamento do organismo como um todo; a distinção entre localização, acesso, contato e conhecimento; e a preservação do recorte analíticocomportamental em situação de análise aplicada do comportamento. Por meio da análise de como estes temas se articulam no discurso skinneriano sobre eventos privados, pretende-se sugerir tanto a possibilidade de uma leitura coerente da independência e complementaridade entre análise do comportamento e fisiologia, quanto algumas condições para tal relação.
Variáveis Biológicas como Constitutivas, mas não Definidoras do Fenômeno Comportamental Privado

Uma ciência comportamental inicia com o fato de que as condições biológicas de um organismo são requisitos para processos comportamentais, na medida em que se está falando de comportamentos de organismos; tais variáveis são constitutivas do fenômeno comportamental, seja ele público ou privado, delimitando as possibilidades de ação do ambiente na produção de respostas do organismo. Mas ainda é necessário analisar a eventual necessidade de referência àquelas condições nas explicações providas por uma ciência do comportamento.

A especificação do status de componentes biológicos em explicações comportamentais é invariavelmente um esforço para esclarecer em que medida a análise comportamental pode ater-se às relações organismocomo-um-todo/eventos-que-lhe-são-externos (cf. Reese, 1996a; 1996b). Quando o tema dos eventos privados é o cerne do debate, o conceito de ambiente interno parece sugerir a participação de eventos internos fisiológicos na própria definição do fenômeno comportamental. É discutindo o alcance do conceito de ambiente interno, portanto, que Skinner (e.g. 1953/1965) oferece as primeiras indicações sobre como equacionar a referência a variáveis biológicas (doravante, serão consideradas basicamente variáveis fisiológicas para a análise do problema).

O ambiente é definido como eventos do universo capazes de afetar o organismo. Skinner (1953/1965) aponta que parte desse universo está sob a pele do organismo (isto é, condições anátomo-fisiológicas podem constituir o ambiente de um organismo), mas destaca dois aspectos: a) um conjunto de eventos do universo torna-se ambiente quando se faz diferenciado para o organismo, a partir da interação deste com contingências de reforçamento que lhe são externas; b) do ambiente, é dito que afeta o organismo e não partes do organismo.

$O$ processo de diferenciação do universo interno (fisiológico) é dependente do mesmo tipo de processo envolvido na diferenciação do mundo físico que cerca o organismo. Universo interno e universo externo são condições para a ocorrência de processos discriminativos de suas partes, mas não definem o fenômeno comportamental propriamente dito. Partes do universo tornam-se partes do ambiente de um organismo quando passam a controlar diferencialmente suas respostas (antes disso, são parcelas do universo indiferenciadas para o organismo). Quando um fenômeno comportamental é descrito, a descrição diz respeito a uma relação, não a um estímulo particular. Uma dor, por exemplo, enquanto 
fenômeno comportamental (isto é, enquanto relação), não é identificada com nenhuma alteração fisiológica específica, embora uma tal alteração possa ser constitutiva de uma relação à qual se denomina "dor". "[Estímulos dolorosos] não são a mesma coisa que a "experiência de dor" (Skinner, 1963/1969, p. 243); sequer são propriamente "estímulos" à parte da relação denominada experiência de dor. Afirmações correlatas podem ser feitas com respeito a relações comportamentais que envolvem elementos do mundo físico. A experiência de umidade não é a mesma coisa que umidade; esta sequer existe enquanto estímulo até que participe de relações comportamentais, isto é, até que o organismo se comporte discriminativamente com respeito a ela.

Os processos através dos quais as variáveis fisiológicas vêm a participar de relações comportamentais delimitam o alcance de explicações nelas baseadas. Em qualquer circunstância, as relações admitidas como propriamente comportamentais são aquelas das quais participa o organismo como um todo; um evento interno controla respostas discriminativas do organismo como um todo. A referência a eventos internos sob a forma de especificação do comportamento de partes do organismo ainda não corresponde a explicações comportamentais. Por exemplo, ao identificar a adoção de explicações neurofisiológicas pelo cognitivismo, Skinner (1990) comenta que "o cérebro é parte do corpo e o que ele faz é parte do que o corpo faz. O que o cérebro faz é parte do que deve ser explicado" (p.1206). Adiante, este tema será retomado, considerando-se especificamente o caso dos comportamentos privados.

Parte significativa da argumentação de Skinner sobre relações comportamentais que envolvem componentes internos consiste na crítica ao mentalismo e à teoria da cópia, segundo a qual o organismo armazena e consulta reproduções internas (mentais) do mundo a sua volta (e.g. Skinner, 1953/1965, 1963/1969). É através da discussão do conceito de sentimento, porém, e de suas relações com os diferentes sistemas de estimulação, que Skinner (e.g. 1963/1969, 1974) analisa de modo mais sistemático a participação de condições fisiológicas em fenômenos comportamentais.

O uso cotidiano do termo sentimento pode envolver tanto a referência a relações comportamentais quanto a eventos que participam destas relações (cf. Skinner, 1989d). "Em certo sentido, o sentimento parece ser tanto a coisa sentida quanto o ato de senti-la" (Skinner, 1963/ 1969, p.255). No que diz respeito ao "ato de sentir", ou ao sentimento enquanto relação comportamental, podese estar falando de respostas discriminativas de condições públicas ou privadas; pode-se sentir a aspereza de uma Psicologia: Reflexão e Crítica, 2000, 13(3), pp.425-434 pedra (estímulo/propriedade de um evento público), ou a contração de um músculo (estímulo/propriedade de um evento privado). É freqüente a confusão entre "ato de sentir" e "coisa sentida", quando o sentimento envolve a discriminação de estímulos privados. Neste caso, a coisa sentida é uma condição corporal, produto colateral da história ambiental do indivíduo (Skinner, 1985) e sua especificação pertence ao campo da anatomia e da fisiologia (Skinner, 1974). A uma ciência do comportamento cumpre explicar os processos através dos quais respostas discriminativas de condições corporais tornam-se possíveis.

Três sistemas nervosos são apontados por Skinner (1974) como requeridos para o contato dos indivíduos com o ambiente, inclusive suas condições corporais: o sistema interoceptivo (através do qual o indivíduo entra em contato com estimulações derivadas dos sistemas digestivo, respiratório e circulatório), o sistema proprioceptivo (através do qual o indivíduo entra em contato com estimulações de músculos, tendões, juntas, etc., particularmente envolvido na discriminação da posição e movimento do corpo) e o sistema exteroceptivo (através do qual o indivíduo entra em contato com estimulação presente no ambiente circundante). Os estímulos que afetam o organismo através daqueles sistemas são designados, correspondentemente, estímulos interoceptivos, proprioceptivos e exteroceptivos. Quando o indivíduo sente algo interno, segundo Skinner, está reagindo discriminativamente a estímulos interoceptivos e proprioceptivos. "Dentre as coisas internas que são sentidas, há os estímulos proprioceptivos e interoceptivos

... Também sentimos o comportamento, incluindo o comportamento muito fraco e as condições que precedem ou estão associadas com o comportar-se" (Skinner, 1963/1969, pp. 255-256). A análise das emoções pode basear-se nesta interpretação. Por exemplo, "respostas reflexas autonômicas a estímulos condicionados estão entre as emoções sentidas - por exemplo, a 'ansiedade' evocada por um estímulo préaversivo" (Skinner, 1963/1969, p.256).

Embora requeridos para o contato com o ambiente, os sistemas interoceptivo, proprioceptivo e exteroceptivo não promovem a discriminação de estímulos ambientais internos, papel reservado às contingências de reforçamento dispostas por uma comunidade verbal. Portanto, nem os estímulos internos se confundem com relações comportamentais, nem os sistemas, também internos, através dos quais se dá o acesso ao mundo de estímulos explicam a participação dos eventos internos em relações comportamentais. $\mathrm{Na}$ análise de eventos 
comportamentais privados, portanto, de modo semelhante ao que ocorre com processos comportamentais considerados públicos, é justificada a indicação de condições fisiológicas que possibilitam o fenômeno, ao mesmo tempo em que é necessário distinguir tais condições das relações comportamentais propriamente ditas.

Autonomia do Recorte Analítico-Comportamental diante dos Fatos Biológicos/Fisiológicos

Se relações comportamentais não se confundem com fatos ou relações ao nível anátomo-fisiológico, justificase que o analista do comportamento, ao lidar com o fenômeno comportamental, limite sua análise à relação organismo-meio, na expectativa de que as ciências biológicas especifiquem algumas das condições que tornam aquelas relações possíveis. Uma explicação comportamental, reconhece Skinner (1987), apresenta lacunas, na medida em que "estímulos e respostas estão separados no tempo e no espaço" (p.782) e tais lacunas só podem ser preenchidas "com os instrumentos e métodos da fisiologia" (p.782). Entretanto, a referência ao que torna as relações comportamentais possíveis não é indispensável para que as relações sejam adequadamente identificadas ou produzidas.

Historicamente, algumas tentativas de promover novas explicações para os fatos comportamentais foram insuficientes, segundo Skinner (1987), para afastar a perspectiva internalista na Psicologia. Thorndike (ainda de acordo com Skinner, 1987), com sua lei do efeito, explicava a própria possibilidade das conseqüências do comportamento afetarem o organismo apelando para sentimentos internos de satisfação/insatisfação (Skinner, ao contrário, relacionou "o efeito fortalecedor de um reforçador operante ao seu valor de sobrevivência na seleção natural da espécie" em 1987, p.782).

O behaviorismo de Watson (1930/1970) buscou uma integração com a Fisiologia, na expectativa de substituição da noção de mediadores mentais para o comportamento por mediadores fisiológicos, acessíveis à investigação empírico-experimental. Watson dedicou-se a uma descrição minuciosa (embora mais especulativa do que sugeria) da fisiologia dos sistemas receptores e efetores, a fim de especificar os componentes internos de relações comportamentais (cf. Watson, 1930/1970). A experiência de Watson, na interpretação de Skinner (1963/1969), não foi produtiva, na medida em que não promoveu uma melhor compreensão do próprio fenômeno comportamental e fomentou uma discussão a respeito de eventos internos ao organismo. Segundo Skinner (1971), “nem a introspecção, nem a fisiologia, provêem informação adequada sobre o que está acontecendo no interior do homem enquanto ele se comporta e ... elas têm o mesmo efeito de desviar a atenção do ambiente externo" (p.195). Ao contrário destas soluções, quando, reconhecendo a existência de eventos privados, uma ciência do comportamento procura explicá-los como fenômenos comportamentais, o afastamento em relação às contingências ambientais não se reproduz, uma vez que os eventos privados estão sendo considerados "não como mediadores fisiológicos do comportamento, mas como parte do próprio comportamento" (Skinner, 1963/ 1969, p. 228).

Não só a ênfase em processos mentais ou fisiológicos tende a afastar o psicólogo das relações propriamente comportamentais. Segundo Skinner (1963/1969), “(a discussão sobre) a importância relativa da dotação genética na explicação do comportamento mostrou ser outra digressão inoportuna" (p.224). Embora reconhecendo a filogênese como nível de seleção do comportamento, Skinner (1990) insistirá no papel das contingências de reforçamento na produção e seleção de instâncias comportamentais observadas de um organismo. Afinal, "independentemente de qualquer dotação genética normal, um organismo variará entre atividade vigorosa e completa quietude, dependendo dos esquemas nos quais tenha sido reforçado" (Skinner, 1971, p.186).

Diferente do que ocorreu com Watson, Skinner afirma ter se distanciado da referência aos fatos biológicos ao iniciar seu programa de pesquisas com o conceito de reflexo. O reflexo, como unidade de análise de uma ciência do comportamento, "não era algo que acontecia dentro do organismo; era uma lei do comportamento" (Skinner, 1987, p.781). Mesmo as "terceiras variáveis" ("condicionamento", “drive" e "emoção"), postuladas como necessárias para a especificação de algumas regularidades do reflexo, eram localizadas "fora do organismo" (Skinner, 1987, p.781), correspondendo a operações realizadas pelo experimentador (embora o programa skinneriano tenha se detido apenas no condicionamento).

Também o fenômeno da percepção, usualmente identificado pela psicologia mentalista com eventos internos mentais ou fisiológicos, pode ser interpretada nos limites do recorte próprio de uma ciência do comportamento. $\mathrm{Na}$ percepção de estímulos (ou propriedades de estímulos) visuais, uma seqüência de eventos físicos e fisiológicos ocorre e é condição para o próprio fenômeno perceptivo (luz refletida, anatomia do aparelho visual, fisiologia da visão, cf. Skinner, 1963/ 1969). A percepção enquanto comportamento, porém, é um responder diferenciado ao mundo circundante, 
produzido por contingências de reforçamento. Neste caso, "aprendemos a perceber no sentido de que aprendemos a responder a coisas de modos particulares por causa das contingências das quais elas são parte" (Skinner, 1971, p.188). Novamente, tanto o mundo físico como estruturas orgânicas são requisitos para o fenômeno, mas não o definem, nem sua indicação permite a identificação das variáveis que podem de fato explicálo. "Não haveria, é claro, nenhuma percepção se não existisse um mundo para ser percebido, mas um mundo que exista não seria percebido se não houvesse contingências apropriadas" (Skinner, 1971, p.187).

Finalmente, se é possível falar de uma autonomia do recorte analítico-comportamental frente ao fatos anátomo-fisiológicos, isso não eqüivale a uma autonomia dos próprios fenômenos comportamentais frente aos fenômenos fisiológicos (ver, a propósito, Reese, 1996a). Os dois conjuntos de fenômenos, de um lado, são interdependentes; de outro, representam níveis diferentes de análise do comportamento dos organismos. Análise do comportamento e fisiologia estudam, cada uma, "parte do episódio comportamental” (Skinner, 1987, p. 782). Se são ciências independentes, são, ao mesmo tempo, ciências complementares. Do ponto de vista de uma Psicologia Comportamental, essa nova relação teria se instituído, segundo Skinner, com sua proposição do reflexo como unidade comportamental (cf. Skinner, 1931/1961).

Limites do Controle do Comportamento por Eventos Internos/Fisiológicos

A possibilidade de controle do comportamento por eventos internos/fisiológicos é usualmente examinada por Skinner como circunscrita por dois limites: as práticas reforçadoras de uma comunidade verbal e os sistemas nervosos que permitem o contato do indivíduo com as partes de seu próprio corpo.

Como o universo em geral, o universo privado, que inclui eventos internos anátomo-fisiológicos, é indiferenciado ao indivíduo até que contingências de reforçamento promovam sua diferenciação (Skinner, 1953/1965, 1974). Estas contingências podem ser de natureza física quando, por exemplo, promovem que partes do corpo controlem discriminativamente seqüências de comportamento motor (andar, pular, etc.), mas são de natureza social quando promovem o controle de respostas descritivas por eventos internos, diante das quais afirma-se que o indivíduo tem consciência (Skinner, 1971). A ênfase nas contingências sociais aparece, portanto, quando se está primariamente interessado em falar da participação de eventos internos no controle de respostas Psicologia: Reflexão e Crítica, 2000, 13(3), pp.425-434 verbais, como descrições de sentimentos, emoções, pensamentos, atitudes, preferências, etc., fenômenos para os quais as teorias psicológicas usualmente se voltam, e com base nos quais postulam determinantes internos para o comportamento.

A dependência de contingências sociais para a aquisição de respostas descritivas de eventos privados decorre da impossibilidade do sujeito autonomamente observar e discernir a ocorrência daqueles eventos em seu corpo. A ação da comunidade verbal, por seu turno, é sempre baseada numa inferência daquelas ocorrências, o que limita o alcance de suas práticas reforçadoras na promoção de repertórios autodescritivos (Skinner, 1945). Dizer que a comunidade infere a ocorrência dos eventos privados significa mais propriamente dizer que ela age com base na observação de eventos públicos, tanto na instalação quanto na manutenção de respostas autodescritivas (Skinner, 1945, 1974). Os problemas decorrentes dos limites da ação da comunidade verbal são examinados por Skinner nas diversas obras nas quais discute o tema dos eventos privados. Considerando os objetivos deste texto, interessará apenas assinalar que, como decorrência da dificuldade de acesso da comunidade verbal aos eventos privados de um indivíduo, as contingências de reforçamento responsáveis pela aquisição de respostas autodescritivas sempre estão baseadas em eventos publicamente observáveis, razão pela qual a precisão de uma descrição de evento privado depende do grau de correspondência deste com os eventos públicos com base nos quais as respostas descritivas foram instaladas e são mantidas (cf. Skinner, 1945, 1974).

Não apenas as práticas reforçadoras de uma comunidade verbal limitam as possibilidades de aquisição de repertórios autodescritivos. O problema original reside na incapacidade do indivíduo discriminar com precisão eventos internos e isso resulta do fato de que "não temos nervos sensórios indo para as partes relevantes do corpo" (Skinner, 1989a, p.33). Voltando a examinar os sistemas nervosos através dos quais o indivíduo entra em contato com o universo público e privado, Skinner aponta que não apenas os sistemas interoceptivos e proprioceptivos, mas também o sistema exteroceptivo "desempenha um papel importante ao observarmos nosso próprio corpo" (Skinner, 1974, p.22). Isso decorre das limitações dos sistemas interoceptivo e proprioceptivo na identificação de alterações anátomo-fisiológicas. Usualmente, estímulos interoceptivos são "os estímulos principais aos quais se reage ao "sentir uma emoção"' (Skinner, 1953/1965, p.261), mas não suficientes enquanto fonte de controle de respostas autodiscriminativas. Por esta razão, "geralmente respondemos a estímulos desse tipo em 
combinação com estimulação exteroceptiva do ambiente circundante e nem sempre identificamos corretamente a fonte de estimulação" (Skinner, 1953/1965, pp.261-262). Uma eventual predominância de estímulos proprioceptivos ou interoceptivos no controle de respostas autodiscriminativas pode ser apenas momentânea e circunstancial, não representando uma autonomia de estímulos desta natureza no controle do comportamento. Diz Skinner (1974): "Estímulos proprioceptivos são dominantes quando uma pessoa descreve seu próprio comportamento no escuro, mas estão estreitamente relacionados com estímulos públicos usados pela comunidade verbal na instrução” (pp.25-26)

Quando Skinner (e.g. 1953/1965, 1974) aponta como limitadas as possibilidades de que eventos internos anátomo-fisiológicos controlem autonomamente respostas autodiscriminativas, o que está sendo indicada é a própria restrição dos sistemas nervosos que colocam o indivíduo em contato com o universo interno, em razão da qual estímulos interoceptivos e proprioceptivos podem controlar respostas autodescritivas apenas parcialmente e em associação com estímulos exteroceptivos. As práticas reforçadoras da comunidade verbal são uma tentativa de superar os limites da privacidade, possibilitando a autodescrição e o acesso público indireto aos eventos privados de um indivíduo, mas o componente inferencial envolvido no reforçamento daquelas respostas compromete a precisão da descrição

O Comportamento Privado como Comportamento do Organismo como um Todo

Foi observado acima que, para Skinner, relações comportamentais são relações do organismo como um todo com o ambiente a sua volta. Não cabe, neste modelo analítico, ater-se ao comportamento de partes do organismo, ainda que relacionando-as a eventos ambientais, simplesmente porque se estaria diante de apenas uma parcela do que deve ser explicado por uma ciência do comportamento. A análise é a mesma para os chamados comportamentos privados ou encobertos. $\mathrm{O}$ conceito de encoberto, aqui, significa apenas inacessibilidade à observação pública direta, em razão de tratar-se de comportamento que ocorre "em escala tão reduzida, que não pode ser observado por outros pelo menos sem instrumentos" (Skinner, 1953/1965, p 263). Enquanto o conceito de estímulo privado pode corresponder a eventos particulares do organismo no contexto de relações comportamentais (assim como o conceito de estímulo público refere-se a eventos particulares do ambiente público que participam de relações comportamentais), o conceito de comportamento encoberto sempre diz respeito ao organismo como um todo, residindo a sua especificidade no limite de observabilidade pública.

O caráter encoberto de um comportamento é, segundo Skinner (1968), função de contingências de reforçamento dispostas no ambiente social. Todo comportamento é originalmente aprendido de forma aberta (publicamente observável) e passa ao nível encoberto como função de contingências sociais específicas. Ao passar para o nível encoberto, muda a observabilidade do comportamento, mas ele continua sendo emitido pelo organismo como um todo.

As teorias mentalistas são apontadas por Skinner (1968) como responsáveis pelo interesse no funcionamento de partes do organismo como modelo de explicação comportamental. Por exemplo, a teoria da cópia, na medida em que supõe a construção de reproduções internas do mundo, ao analisar o comportamento de ver, terá que postular este comportamento como executado por uma parte do organismo, que consulta um conteúdo interno com o qual não se confunde (cf. Skinner, 1968). Numa explicação comportamental, ao contrário, o ver, público ou privado, é sempre um comportamento do organismo como um todo e o fato de ser emitido na ausência da coisa vista significa apenas que uma vez aprendido de forma aberta pode ser emitido de forma encoberta, sem o suporte dos estímulos que estavam presentes durante o processo de aquisição da resposta (cf. Skinner, 1945, 1953/1965, 1968).

O interesse pelo cérebro na explicação do comportamento também está associado à aceitação da teoria da cópia e é apontado por Skinner (1985) como derivado da adesão do cognitivismo à teoria da informação, de acordo com a qual o organismo processa internamente informações abstraídas do ambiente e como resultado deste processamento se comporta. O "órgão processador" é o cérebro, e assim passa-se a falar de comportamentos humanos como comportamentos de parte do organismo. "Obviamente, não se diz que é o organismo como um todo que vê uma representação da realidade; é uma parte menor dele. A ciência cognitiva é forçada a dizer isso quando assume como modelo a teoria da informação" (Skinner, 1985, p. 293).

A análise de comportamentos como o ver na ausência da coisa vista, enquanto comportamento encoberto do organismo como um todo, exigirá grande esforço interpretativo por parte de Skinner. Ela é necessária, porém, para a própria sustentação do recorte analíticocomportamental como pertinente à investigação de problemas característicos do campo da psicologia, como 
o pensar, o imaginar, etc. A proposição do comportamento encoberto como comportamento do organismo como um todo representa, portanto, mais um modo de defender um recorte de análise psicológico/ comportamental, que não se confunde, em nenhum momento, com o domínio das ciências biológicas, embora possa ser complementado pelas informações geradas neste domínio.

\section{A Distinção entre Localização, Acesso, Contato e Conhecimento}

Pertence à tradição mentalista em psicologia a suposição de que cada indivíduo tem um mundo interior, com o qual cultiva uma relação única, que em certa medida é incomunicável e determinante de seus comportamentos. São os sentimentos experimentados internamente, os pensamentos secretos, etc., que não podem ser conhecidos em sua manifestação genuína por mais ninguém e que controlam o comportamento privado e público. Skinner (e.g. 1963/1969) não rejeita a existência deste mundo interno ou o modo particular como ele é experimentado por cada um, mas ao reconhecer que eventos anátomo-fisiológicos podem participar de relações comportamentais, não apenas contraria a tradição mentalista, apontando que tudo que o indivíduo sente é o seu próprio corpo, como também questiona a própria possibilidade de conhecimento privilegiado do que se passa no interior de cada um.

Para questionar o caráter privilegiado do autoconhecimento, Skinner (e.g. 1945, 1953/1965, 1963/ $1969,1974)$ discute, em diferentes momentos, quatro aspectos da participação de eventos internos em relações comportamentais: a localização, o contato, a acessibilidade e o conhecimento. Uma confusão entre estes aspectos tem propiciado a propagação de postulados internalistas acerca do comportamento humano.

Continuando com a problemática específica dos eventos anátomo-fisiológicos, pode-se dizer que alguns deles se convertem em estímulos interoceptivos ou proprioceptivos, na medida em que passam a participar de relações comportamentais. Estímulos interoceptivos e proprioceptivos estão localizados sob a pele do organismo e, portanto, podem ser considerados estímulos internos. É preciso lembrar, porém, que alguns estímulos relativos ao próprio organismo não estão propriamente dentro dele; por exemplo, o "suar" de um sujeito é uma alteração fisiológica que não se localiza sob a pele, e com o qual o próprio indivíduo pode entrar em contato através do sistema exteroceptivo.

Quando um estímulo interoceptivo ou proprioceptivo participa de relações comportamentais, pode-se dizer que Psicologia: Reflexão e Crítica, 2000, 13(3), pp.425-434 o contato do próprio indivíduo com aquele evento é especial, no sentido de que a estimulação que o afeta é diferente daquela provida pelo contato que outros podem estabelecer com o mesmo evento. Skinner reconhece que "estímulos proprioceptivos e interoceptivos têm uma certa intimidade" (Skinner, 1963/1969, p. 230); com eles o indivíduo tem um "contato especial" (Skinner, 1963/ 1969, p. 225), um "contato íntimo" (Skinner, 1974, p. 22), mas isso significa apenas que a forma de estimulação não pode ser a mesma para outros. Por exemplo, "ninguém mais pode estabelecer o mesmo tipo de contato com [um dente inflamado]" (Skinner, 1953/1965, p. 257) que o próprio sujeito estabelece. De certo modo, a noção de privacidade significará, para Skinner (1963/1969), que cada indivíduo "está sujeito de forma única a certos tipos de estimulação interoceptiva e proprioceptiva” (p.226).

Reconhecido o caráter interno (localização) e familiar (tipo de contato) de certas estimulações anátomofisiológicas, as estimulações interoceptivas e proprioceptivas, a isso não corresponde um acesso ou conhecimento privilegiado. Como apontado anteriormente, o sujeito depende de contingências sociais para a aquisição e manutenção de repertórios autodiscriminativos.

O conceito de acessibilidade diz respeito não à localização, mas à possibilidade de condicionamento de respostas discriminativas. Considerando esta dimensão como apropriada para a definição do caráter público ou privado de um evento, consideram-se públicos os estímulos com respeito aos quais a comunidade pode condicionar respostas discriminativas de modo direto; são privados, por seu turno, eventos com respeito aos quais respostas discriminativas não podem ser diretamente condicionadas. Estímulos interoceptivos e proprioceptivos são privados no sentido de acessibilidade restrita; como decorrência, "nós usualmente respondemos a estímulos deste tipo em combinação com estimulação exteroceptiva do ambiente circundante" (Skinner, 1953/ 1965, p. 261). (Deve ser observado que a estimulação exteroceptiva que participa de processos discriminativos deste tipo pode ser originada do próprio corpo do indivíduo; podem ser mudanças em seu próprio aparato anátomo-fisiológico).

Conhecimento significa, de uma perspectiva analíticocomportamental, repertório discriminativo. Quando se está lidando com problemas como sentimentos e pensamentos, o repertório discriminativo envolvido é especialmente o verbal. Aos limites de acessibilidade dos eventos interoceptivos e proprioceptivos, em que pese a intimidade do contato que o indivíduo com eles estabelece, corresponde uma restrição no conhecimento 
possível daqueles eventos. Como afirma Skinner, a intimidade dos estímulos interoceptivos e proprioceptivos "não significa que possam ser conhecidos mais facilmente ou mais diretamente" (Skinner, 1963/1969, p. 230). Na medida em que o conhecimento daqueles eventos dependerá de contingências sociais, e que estas terão como base estímulos exteroceptivos, o conhecimento dos eventos privados será indireto e impreciso

Skinner (1989a) não ignora a importância que a cultura passa a atribuir à observação e discriminação de eventos internos. Esta valorização é parcialmente justificada pelo caráter informativo dos relatos autodescritivos sobre probabilidade de comportamento futuro do sujeito. De todo modo, essas autodiscriminações são um produto cultural e compõem o que Skinner (1989a) denominará de self. Para ele, filogênese, ontogênese e cultura produzem, respectivamente, o organismo, a pessoa e o self. "Uma pessoa, enquanto repertório de comportamento, pode ser observada por outros; o self, como conjunto de estados internos que acompanham só é observado através do sentimento e da introspecção" (Skinner, 1989a, p. 28).

Com a distinção entre localização, contato, acesso conhecimento, Skinner compatibiliza um reconhecimento da natureza especial do contato que o indivíduo estabelece com seu próprio corpo com a explicação do porquê este contato não corresponde a um conhecimento privilegiado, mas, ao contrário, a restrições ao autoconhecimento. Esta postura é inteiramente original na psicologia e inverte a lógica que justificava alguns postulados mentalistas, como a proposição de uma base interna e mais precisa para respostas autodescritivas frente a descrições de terceiros (o tradicional problema de asserções na primeira e na terceira pessoas). Da perspectiva skinneriana, por mais estranho que pareça, "é a comunidade que ensina o indivíduo a conhecer-se" (Skinner, 1953/1965, p. 261), ainda que cada um tenha de fato uma relação especial com o que lhe ocorre internamente.

A Preservação do Recorte AnalíticoComportamental em Situação de Análise Aplicada do Comportamento

Até aqui, a análise apontou fundamentalmente como a ciência skinneriana equaciona a referência a componentes internos fisiológicos para sustentar a definição de um recorte investigativo que se volta para as relações do organismo como um todo com os eventos que lhe são externos. Foi apontado, porém, que a independência de recortes da análise do comportamento e fisiologia não representa uma independência dos fenômenos investigados por cada ciência. Cabe, então, discutir adicionalmente a possibilidade de, em situação aplicada, a análise do comportamento confinar-se ao seu recorte relacional. A questão é polêmica, provavelmente por ser atravessada por problemas diversos (por exemplo, o efeito de restrições anátomo-fisiológicas geneticamente determinadas, as mudanças na sensibilidade a contingências produzidas por processos maturacionais, efeitos imediatos de alterações fisiológicas decorrentes de história ambiental, etc.), que não podem ser facilmente organizados num sistema interpretativo simples e compatível com práticas culturais fortemente instituídas (por exemplo, tratamento farmacológico de "problemas mentais", diagnóstico clínico orientado por sistema de classificação por síndrome, etc.). Ainda assim, é possível falar de autonomia do recorte analítico-comportamental em situação aplicada, o que Skinner faz considerando exatamente a intervenção clínica. Em um texto de 1988 (Skinner, 1988/1989b), tanto o internalismo mentalista quanto o fisiológico são rejeitados como modelo para a análise e intervenção do terapeuta comportamental.

Skinner (1988/1989b) fala da psicoterapia como a psicologia clínica de caráter internalista, e da terapia comportamental como modelo de intervenção baseado em supostos analítico-comportamentais. A primeira "tem freqüentemente preocupado-se com sentimentos, ansiedade, medo, raiva e coisas do tipo" (p. 74), enquanto terapeutas comportamentais se voltam para a história ambiental. Isso ocorre porque, para o analista do comportamento, "o comportamento problemático é causado por contingências de reforçamento problemáticas e não por sentimentos ou estados da mente problemáticos e nós podemos corrigir o problema corrigindo as contingências." (p. 74)

Uma vez que o sentimento seja identificado com uma condição anátomo-fisiológica que pode vir a participar de relações comportamentais, é preciso também notar que se trata de um produto da história ambiental do sujeito, tanto quanto o comportamento que precisa ser explicado. "Para cada estado sentido e denominado de sentimento, há presumivelmente eventos ambientais anteriores dos quais ele é função. A terapia comportamental dirige a atenção para o evento anterior, não o sentimento." (Skinner, 1988/1989b, p. 74)

O aparato anátomo-fisiológico produzido pela história ambiental (filogenética e ontogenética) é reconhecido como um aspecto relevante do fenômeno comportamental. "Como as contingências de reforçamento operante afetam processos fisiológicos é uma questão indubitavelmente importante" (Skinner, 1988/1989b, p. 82). No entanto, o terapeuta comportamental, no uso de métodos de avaliação e 
intervenção próprios da análise do comportamento, pode prescindir da referência àqueles eventos e daquele nível de análise do fenômeno comportamental. A suposição contrária, de que os métodos analítico-comportamentais são menos seguros, pode levar à adesão ao recorte internalista e não se justifica. "Os terapeutas comportamentais podem também se voltar para a fisiologia se não confiam em seus próprios métodos, mas seus métodos são tão objetivos quanto os da fisiologia." (p.82)

Tanto o internalismo mentalista quanto o fisiológico são reproduzidos no contexto de práticas culturais importantes e certamente não está ao alcance de um terapeuta comportamental promover a superação de tais práticas, mas aderir a elas corresponde a deixar de investigar e intervir com respeito às relações comportamentais propriamente ditas. Diz Skinner (1988/ 1989b):

"Não se pode brigar com a escolha da ciência médica como campo profissional, ou mesmo com os filósofos que pretendem examinar suas mentes através da introspecção, mas para cada terapeuta comportamental que, após descobrir um fato sobre o comportamento, procura uma explicacão fisiológica, bá um terapeuta a menos para estudar mais o próprio comportamento." (p.82, grifo dos autores)

\section{Considerações Finais}

A definição das condições de independência e complementaridade entre análise do comportamento e fisiologia tem se mostrado um assunto polêmico na literatura behaviorista radical e parece demandar, para ser equacionada, uma elaboração teórica consistente, como também (e, talvez, principalmente) pesquisa empírica sistemática, especialmente na área de aplicação clínica, onde o modelo analítico-comportamental apenas recentemente começou a ser explorado com maior intensidade (e onde as práticas culturais - também favorecem fortemente recortes internalistas). É possível dizer que a polêmica se alimenta parcialmente de afirmações de Skinner, que, como reconhecido no início deste texto, não são sempre coerentes. Mas exatamente dos escritos de Skinner é possível derivar elementos que orientem de forma coerente a demarcação das fronteiras entre as duas ciências.

Nas obras aqui consideradas, nas quais o tema dos eventos privados constitui o interesse central, o modo como Skinner equaciona a referência à Fisiologia pode ser organizado num quadro definido pelas seguintes proposições: a) os sistemas interoceptivo, proprioceptivo e exteroceptivo são condição para o fenômeno comportamental privado, mas não definem aquela relação; b) estímulos interoceptivos e proprioceptivos não controlam autonomamente respostas autodescritivas; c) descrições do funcionamento de partes do organismo não são descrições comportamentais; d) localização, contato, acesso e conhecimento dizem respeito a aspectos diversos da relação organismo-ambiente, inclusive privado; e) no caso da estimulação interoceptiva ou proprioceptiva, a natureza diferenciada do contato está associada a restrições no acesso e impossibilidade do conhecimento; f) o recorte analítico comportamental frente aos fatos anátomo-fisiológicos tem validade não apenas enquanto campo de investigação, mas é pertinente também enquanto limite de intervenção.

O quadro definido acima representa, antes de tudo, uma contribuição original ao campo da Psicologia, capaz de estabelecer o domínio próprio de uma ciência comportamental frente a ciências com as quais a psicologia pode interagir proveitosamente para produzir soluções para os problemas humanos, mas diante das quais necessita afirmar seu recorte próprio de investigação e análise. Representa, também, uma leitura não apenas possível das proposições skinnerianas, mas uma leitura que pode ser argumentada como consistente com a proposição de comportamento enquanto fenômeno que diz respeito à relação do organismo como um todo com eventos ambientais que lhe são externos.

\section{Referências}

Baer, D. (1996). On the invulnerability of behavior-analytic theory to biological research. The Behavior Analyst, 19, 83-84.

Bullock, D. (1996). Toward a reconstructive understanding of behavior: A response to Reese. The Behavior Analyst, 19, 75-78.

Donahoe, J. W. (1996). On the relation between behavior analysis and biology. The B

Donahoe, J W. \& Palmer, D. C (1994). Learning and complex behavior. Boston/London: Allyn and Bacon.

Flora, S. R. \& Kestner, J. (1995). Cognitions, thoughts, private events, etc. are never initiating causes of behavior: Reply to Overskeid. Psychological Record, 45, 577-589

Hayes, L. J. (1994) Thinking. Em S. C. Hayes, L. J. Hayes, M. Sato, \& K. Ono (Orgs.), Behavior analysis of language and cognition (pp.149-164). Reno, Nevada: Context Press.

Moore, J. (1975). On the principle of operationism in a science of behavio Behaviorism, 3, 120-138.

Moore, J. (1981). On mentalism, methodological behaviorism, and radical behaviorism. Behaviorism, 9, 55-77.

Moore, J. (1997). Some thoughts on the S-R issue and the relation between behavior analysis and behavioral neuroscience. Journal of the Experimental Analysis of Behavior, 67, 242-245.

Overskeid, G. (1994). Private events and other causes of behavior: Who can tell de difference? Psychological Record, 44, 35-43.

Poling, A. \& Byrne, T. (1996). Reactions to Reese: Lord, let us laud and lament. The Behavior Analyst, 19, 79-82.

Reese, H. W. (1996a). How is physiology relevant to behavior analysis? The Behavior Analyst, 19(1), 61-70. 
434 Emmanuel Zagury Tourinbo, Eveny da Rocha Teixeira \& Josiane Miranda Maciel

Reese, H. W. (1996b). Response to commentaries. The Beharior Analyst $19,85-88$.

Skinner, B. F. (1945). The operational analysis of psychological term Psychological Revien, 52, 270-277/291-294.

Skinner, B. F. (1961). The concept of the reflex in the description of behavior. Em B. F. Skinner (Org.), Cumulative Record - Enlarged Edition (pp 319-346). New York: Appleton-Century-Crofts. (Original publicado em 1931)

Skinner, B. F. (1965). Private events in a natural science. Em B. F. Skinner (Org.), Science and buman behavior (pp 257-282). New York/London: Free Press/Collier MacMillan. (Original publicado em 1953)

Skinner, B. F. (1968). Teaching thinking. Em B. F. Skinner (Org.), The technology of teaching (pp.115-144). New York Appleton-Century-Crofts Skinner, B. F. (1969). Behaviorism at fifty. Em B. F. Skinner (Org.), Contingencies of reinforcement: $A$ theoretical analysis (pp. 221-268). New York Appleton-Century-Crofts. (Original publicado em 1963)

Skinner, B. F. (1971). What is man. Em B. F. Skinner (Org.), Beyond freedom and dignity (pp.184-215). New York: Alfred A. Knopf.

Skinner, B. F. (1974). The world within the skin. Em B. F. Skinner (Org.), About bebaviorism (pp.21-32). New York: Alfred A. Knopf.

Skinner, B. F. (1985). Cognitive Science and Behaviorism. British Journol of Psychology, 76, 291-301.

Skinner, B. F. (1987). Whatever happened to psychology as the science of behavior? American Psychologist, 42, 780-786.

Skinner, B. E. (1989a). The initiating self. Em B. F. Skinner (Org.), Recent issues in the analysis of behavior (pp. 27-33). Columbus, Ohio: Merrill.
Skinner, B. F. (1989b) The operant side of behavior therapy. Em B. F. Skinner (Org.), Recent issues in the analysis of behavior (pp.73-84). Columbus, Ohio: Merrill. (Original publicado em 1988)

Skinner, B. F. (1989c) The origins of cognitive thought. American Psychologist, 44, $13-18$.

Skinner, B. F. (1989d). The place of feeling in the analysis of behavior. Em B. F. Skinner (Org.), Recent issues in the analysis of behavior (pp.3-11). Columbus, Ohio: Merrill.

Skinner, B. F. (1990). Can psychology be a science of mind? American Psycbolooist, 45, 1206-1210.

Stemmer, N. (1995). Explanatory and predictive roles of inner causes: A reply to Overskeid. Psycbological Record, 45, 349-354.

Tourinho, E. Z. (1999). Conseqüências do externalismo behaviorista radical. Psicologia: Teoria e Pesquisa, 15, 107-115.

Tourinho, E. Z. (1997). Evento privado: Função e limites do conceito. Psicologia: Teoria e Pesquisa, 13, 203-209.

Watson, J. B. (1970) Behaviorism. New York: Norton Library. (Original publicado em 1930)

Sobre os autores:

Emmanuel Zagury Tourinho é Psicólogo, Doutor em Psicologia pela Universidade de São Paulo, Bolsista do CNPq e Docente do Departamento de Psicologia Experimental e do Programa de PósGraduação em Teoria e Pesquisa do Comportamento da Universidade Federal do Pará.

Eveny da Rocha Teixeira é graduanda em Psicologia na Universidade Federal do Pará e Bolsista de Iniciação Científica no Programa PIBIC/CNPq.

Josiane Miranda Maciel é graduanda em Psicologia na Universidade Federal do Pará e Bolsista de Iniciação Científica no Programa PIBIC/CNPq.

Recebido em 27.07.1999 Revisado em 24.09.1999 Aceito em 24.01.2000 